\title{
Comparação da sensibilidade de bovinos e búfalos à intoxicação por Palicourea marcgravii (Rubiaceae) ${ }^{1}$
}

\author{
José Diomedes Barbosa ${ }^{2}$, Carlos Magno Chaves de Oliveira ${ }^{2}$, Carlos Hubinger \\ Tokarnia $^{3}$ e Franklin Riet-Correa ${ }^{4}$
}

\begin{abstract}
Barbosa J. D., Oliveira C. M. C., Tokarnia C. H. \& Riet-Correa F. 2003. [Comparison of the sensibility of cattle and buffaloes to poisoning by Palicourea marcgravii (Rubiaceae).] Comparação da sensibilidade de bovinos e búfalos à intoxicação por Palicourea marcgravii (Rubiaceae). Pesquisa Veterinária Brasileira 23(4):167-172. Escola de Medicina Veterinária, Campus Castanhal, Universidade Federal do Pará, Rua Maximino Porpino 1000, Castanhal, PA 68743080, Brazil. E-mail: diomedes@ufpa.br

In order to verify if buffaloes are more resistant than cattle to poisoning by Palicourea marcgravii, the plant was given per os simultaneously to buffaloes and cattle. Seven buffaloes and three head of cattle were used. Doses of $0.5,1.0$ and $2.0 \mathrm{~g} / \mathrm{kg}$ did not cause signs of poisoning in buffaloes; but doses of 3.0, 4.0 and $6.0 \mathrm{~g} / \mathrm{kg}$ caused death. In cattle $0.25 \mathrm{~g} / \mathrm{kg}$ did not cause symptoms; but 0.5 and $2.0 \mathrm{~g} / \mathrm{kg}$ were lethal. The influence of exercise on the onset of symptoms, the time which elapsed from the beginning of the administration of the plant to the appearance of symptoms, and the symptoms themselves, were similar in the two animal species. The clinical course was longer in buffaloes; whilst in cattle the period between the onset of severe symptoms and death lasted 9 to 17 minutes; in buffaloes it varied from 10 minutes to 1 hour 28 minutes. It can be concluded, that buffaloes are about six times more resistant than cattle to the toxic action of $P$. maracgravii. The lower incidence of deaths in buffaloes by poisonous plants in the Amazon region is, at least in part, due the lower sensibility of buffaloes to poisoning by this plant. Another factor responsible for the smaller number of buffaloes which die due to plant poisoning in the Amazon region, is possibly that buffaloes prefer the lowlands, e.g. temporarily flooded areas, which are the habitat of Arrabidaea bilabiata, the second most important poisonous plant of the Amazon region. This plant is less poisonous than $P$. marcgravii, and its habitat are the higher not flooded areas. So it would be safer, in order to diminish losses, to breed buffaloes instead of cattle in areas where $P$. marcgravii occurs. The reason for the greater resistance of buffaloes should be further investigated as a possible prophylactic measure to avoid poisoning by $P$. marcgravii in cattle. On the other hand, Australian investigators modified genetically the ruminal bacteria Butyrivibrio fibrisolvens by introducing a gene, isolated from a Moraxella sp, which codifies a dehalogenase, capable of hydrolyzing fluoroacetate, the poisonous principle of $P$. marcgravii. Transferring the genetically modified $B$. fibrisolvens into the rumen of animals, which consume plants that contain fluoroacetate, would be a viable method to control that poisoning through a ruminal detoxifying process for the toxin. Through preliminary contacts, the director of the consorcium in Australia, responsible for the modification of the bacteria, declared that he is interested to sell the technology to our country, but it would be necessary to know if it is permitted to introduce
\end{abstract}

${ }^{1}$ Recebido em 16 de abril de 2003.

Aceito para publicação em 22 de julho de 2003.

${ }^{2}$ Escola de Medicina Veterinária, Campus Castanhal, Universidade Federal do Pará, Rua Maximino Porpino 1000, Castanhal, PA 68743-080. E-mail: diomedes@ufpa.brecmagno@ufpa.br

\footnotetext{
${ }^{3}$ Depto Nutrição Animal e Pastagem, Instituto de Zootecnia, Universidade Federal Rural do Rio de Janeiro (UFRRJ), Seropédica, RJ 23835-000. E-mail: tokarnia@ufrrj.br

${ }^{4}$ Centro de Saúde e Tecnologia Rural, Universidade Federal de Campina Grande, Campus de Patos, Jatobá, Patos, Paraíba 58700-000. E-mail: rmtmed@cstr.ufpb.br
} 
into Brazil the genetically modified bacteria. If allowed, it would be necessary to perform investigations on the viability and the methodology for using this bacteria to control $P$. marcgravii poisoning in our country.

INDEX TERMS: Poisonous plants, plant poisoning, Palicourea marcgravii, Rubiaceae, cattle, buffaloes, prophylaxis, Butyrivibrio fibrisolvens, genetically modified bacteria.

RESUMO.- O presente estudo foi realizado para verificar se búfalos são mais resistentes do que bovinos à ação tóxica de Palicourea marcgravii, mediante a administração da planta por via oral, simultaneamente, a bovinos e a búfalos. Foram usados sete búfalos e três bovinos. Verificou-se que em búfalos doses de $0,5 \mathrm{~g} / \mathrm{kg}, 1,0 \mathrm{~g} / \mathrm{kg}$ e 2,0 g/ $\mathrm{kg}$ não causaram sintomas de intoxicação. As doses de 3,0 g/kg, 4,0 g/kge 6,0 g/ $/ \mathrm{kg}$ causaram a morte dos búfalos. Em bovinos, a dose de $0,25 \mathrm{~g} / \mathrm{kg}$ não causou sinais clínicos de intoxicação, enquanto que doses de $0,5 \mathrm{~g} / \mathrm{kg}$ e $2,0 \mathrm{~g} / \mathrm{kg}$ causaram a morte. A influência do exercício sobre o aparecimento dos sintomas, o prazo decorrido desde o começo da administração da planta até o início de sintomas, e os próprios sintomas, foram semelhantes nas duas espécies animais. O curso clínico foi mais longo nos búfalos. Enquanto nos bovinos o período entre o aparecimento dos sintomas graves e a morte foi de 9 a 17 minutos, nos búfalos variou de 10 minutos a 1 hora e 28 minutos. Pode se concluir que os bubalinos são aproximadamente seis vezes mais resistentes do que os bovinos à ação tóxica de $P$. marcgravii. $\mathrm{O}$ menor índice de mortes pela ação de plantas tóxicas na Amazônia em búfalos é, pelo menos em parte, devido à maior resistência do búfalo à intoxicação por essa planta. Outro fator responsável pelo menor número de mortes em búfalos pela intoxicação por plantas, na Amazônia, poderia ser que os búfalos preferem a várzea, que é o habitat de Arrabidaea bilabiata, a segunda planta tóxica mais importante da Amazônia, menos tóxica do que $P$. marcgravii, e com habitat na terra firme. Em áreas onde ocorre $P$. marcgravii seria mais prudente, para diminuir os prejuízos, criar búfalos em lugar de bovinos. A causa dessa maior resistência do búfalo merece ser investigada para a eventual elaboração de métodos profiláticos da intoxicação por $P$. marcgravii em bovinos. Por outro lado, pesquisadores australianos modificaram geneticamente a bactéria ruminal Butyrivibrio fibrisolvens, mediante a introdução de um gene, isolado de Moraxella sp, que codifica uma dehalogenase, capaz de hidro-lizar fluoroacetato. A transferência de $B$. fibrisolvens geneticamente modificado para o rúmen de animais ingerindo plantas que contêm fluoroacetato, como é o caso de P. marcgravii, seria um método viável para o controle da intoxicação mediante a detoxificação ruminal do princípio ativo. Em contatos preliminares o diretor responsável do consórcio na Austrália responsável pela modificação da bactéria, declarou o interesse em vender a tecnologia ao nosso país, porém seria necessário saber se é possível importar essa bactéria geneticamente modificada no Brasil. Caso positivo, seria indispensável realizar pesquisas sobre a viabilidade e a metodologia para o uso dessa bactéria em nosso meio.

TERMOS DE INDEXAÇÃO: Intoxicação por planta, Palicourea marcgravii, Rubiaceae, bovinos, búfalos, profilaxia, Butyrivibrio fibrisolvens, bactérias geneticamente modificadas.

\section{INTRODUÇÃO}

Palicourea marcgravii (Rubiaceae) é a planta tóxica mais importante para bovinos no Brasil devido a sua extensa distribuição, boa palatabilidade, alta toxidez e efeito acumulativo (Tokarnia et al. 1979). Anualmente morre, estimativamente, um milhão de bovinos por ação de plantas tóxicas no Brasil (Riet-Correa \& Medeiros 2001). Na região amazônica, onde morre a metade dos bovinos vitimados por plantas tóxicas no Brasil, ela é responsável por aproximadamente $80 \%$ de todas as mortes causadas por intoxicações por plantas. Convém ressaltar que as plantas tóxicas são a causa mais importante de mortes de bovinos adultos nessa extensa região (Tokarnia et al. 1979).

0 tratamento de animais intoxicados por P. marcgravii não é viável, mesmo que se conhecesse um tratamento, devido à evolução superaguda da intoxicação. Por outro lado, os únicos métodos profiláticos conhecidos são cercar bem as áreas infestadas ou erradicar a planta, medidas que tem tido resultados insatisfatórios. É preciso, portanto, procurar outros métodos profiláticos mais eficientes para diminuir as perdas econômicas causadas por esta intoxicação.

As informações que se obtém freqüentemente na região amazônica, mencionam que os búfalos são mais resistentes à intoxicação por plantas, isto é, que morrem menos búfalos que bovinos intoxicados por plantas.

Já está bem estabelecido que as duas plantas tóxicas mais importantes da região amazônica são Palicourea marcgravii, na terra firme, e Arrabidaea bilabiata, na várzea. Em Roraima em vez de A. bilabiata ocorre Arrabidaea. japurensis, de habitat e ação semelhantes.

O menor número de mortes de búfalos devido à ação de plantas tóxicas pode ser explicado por dois motivos. Um motivo parece ser a diferença no habitat preferencial para as duas espécies. Na terra firma, habitat preferencial dos bovinos, a planta mais freqüente é $P$. marcgravii, que é mais tóxica e é consumida em quaisquer condições, mesmo sem fome; enquanto que na várzea, o habitat preferencial dos búfalos, a planta mais freqüente é $A$. bilabiata, que é menos tóxica que P. marcgravii e é consumida somente em condições de fome. Por exemplo, uma fazenda da região amazônica onde havia as duas plantas em abundancia, nos seu respectivo habitat, $o$ fazendeiro relatou que criava bovinos, sempre tendo grandes perdas por morte. Foi aconselhado a criar búfalos em vez de bovinos, e o número de mortes diminuiu consideravelmente. Observou-se que o curral estava situado em terra firme; soltos os búfalos, estes se dirigiam às extensas várzeas onde havia $A$. bilabiata e onde os búfalos ficavam a maior 
parte do tempo. Por outro lado, os bovinos, de acordo com o histórico do criador, quando soltos, se dirigiam aos pastos de terra firme, entremeados de capoeiras e matas e onde $P$. marcgravii era abundante, ocorrendo mortes freqüentes, principalmente quando os bovinos eram movimentados (Tokarnia 1978, dados não publicados).

O segundo motivo seria uma maior resistência (tolerância) natural ou adquirida dos búfalos. Por exemplo, em uma publicação é fornecido o histórico, de acordo com o qual em uma propriedade constituída só de terra firme, comparativamente, as mortes de búfalos devido a $P$. marcgravii, existente nesta propriedade, eram bem menos frequientes do que as de bovinos (Cunha 1987).

De uma maneira geral, os dados obtidos através de pesquisas em bovinos são aceitos para búfalos. Porém, considerando que existem diferenças na capacidade digestiva, hábitos alimentares e outros aspectos da fisiologia e da bioquímica dos búfalos em relação aos bovinos, é necessário que a toxidez das diversas plantas seja estabelecida para búfalos.

$O$ presente estudo foi realizado para verificar se os búfalos são mais resistentes que os bovinos à ação de $P$. marcgravii, mediante a administração simultânea da planta por via oral em doses iguais a animais das duas espécies.

\section{MATERIAL E MÉTODOS}

No presente estudo foram utilizados sete búfalos e três bovinos, com 1 a 2 anos idade, machos, com exceção do búfalo 5591 e do bovino 5599, que eram fêmeas. No início do experimento pesavam entre 165 e $293 \mathrm{~kg}$. Eram mantidos em piquete de Brachiaria brizantha, com água à vontade. Aproximadamente 12 horas antes da administração da planta os animais foram separados em um curral e deixados em jejum. Os exames clínicos e a administração foram feitos em um tronco de contenção. Com relação ao quadro clínico, foram verificadas as frequiências cardíaca e respiratória, a freqüência e a intensidade dos movimentos ruminais e a temperatura. Doses previamente determinadas das folhas de Palicourea marcgravii eram colocadas na boca dos animais contidos, que prontamente as mastigavam e deglutiam. Em seguida à administração da planta os animais eram soltos novamente no piquete onde eram observados. A intervalos de aproximadamente 12 horas eram movimentados durante 15 minutos, geralmente a cavalo, às vezes a pé, durante dois dias (ao todo eram movimentados quatro vezes). Quando apresentavam sintomas, eram filmados e dentro do possível, examinados clinicamente (geralmente os animais faziam movimentos desordenados e/ou movimentos de pedalagem vigorosos). No caso de morte, era realizada imediatamente a necropsia, com coleta de fragmentos dos principais órgãos em solução de formol a $10 \%$, para exames histopatológicos. $\mathrm{O}$ material foi processado rotineiramente e corado pela Hematoxilina-Eosina (HE).

A planta procedia dos municípios do Rondon do Pará e Abel Figueiredo, Pará. Foi coletada no dia 19 de outubro de 2002 e sempre conservada em geladeira, com exceção durante a viagem de ônibus de 8 horas, durante a qual foi mantida em saco de pano molhado. Tratava-se de folhas verdes bastante coriáceas, que não murcharam nem secaram durante todo período do experimento, que se estendeu de 20 a 25 de outubro de 2002.

Os experimentos foram realizados na Fazenda Curicaca, município de Castanhal, Pará. Os exames histopatológicos foram realizados no Projeto Sanidade Animal, UFRRJ.

\section{RESULTADOS}

No Quadro 1 consta o delineamento dos experimentos, com dados sobre os desfechos. Detalhes dos experimentos realizados constam nos resumos dos protocolos.

Verificou-se que em relação aos búfalos as doses de $0,5 \mathrm{~g} /$ $\mathrm{kg}, 1,0 \mathrm{~g} / \mathrm{kg}$ e $2,0 \mathrm{~g} / \mathrm{kg}$ não causaram sintomas de intoxicação. As doses de $3,0 \mathrm{~g} / \mathrm{kg}, 4,0 \mathrm{~g} / \mathrm{kg}$ e $6,0 \mathrm{~g} / \mathrm{kg}$ provocaram a morte dos búfalos. Em relação aos bovinos, só a dose de 0,25 $\mathrm{g} / \mathrm{kg}$ não causou sintomas de intoxicação. As doses de $0,5 \mathrm{~g} /$ $\mathrm{kg} 2,0 \mathrm{~g} / \mathrm{kg}$ provocaram a morte dos bovinos.

Os Búfalos $5595(4 \mathrm{~g} / \mathrm{kg})$ e $5584(3,0 \mathrm{~g} / \mathrm{kg})$ mostraram sintomas e morreram independentemente de exercício. 0 búfalo $5587(6 \mathrm{~g} / \mathrm{kg})$ mostrou sintomas de intoxicação e morreu durante a movimentação. 0 tempo durante $o$ qual $o$ búfalo 7 foi movimentado até o aparecimento dos sintomas graves, foi um minuto. Os primeiros sintomas de intoxicação foram observados nos búfalos entre 8 h e 28 h 17 min. após o começo da administração da planta e tiveram a duração de $10 \mathrm{~min}$. a $1 \mathrm{~h} 28 \mathrm{~min}$. Um búfalo $\left(\mathrm{n}^{\circ} .5595-4 \mathrm{~g} / \mathrm{kg}\right)$ já 9 h 47 min. após o começo da administração da planta mostrou sintomas leves sob a forma de andar lento e de ficar muito tempo em decúbito esternal durante o período de exercício.

O Bovino $5597(2 \mathrm{~g} / \mathrm{kg})$ após ter sido movimentado intermitentemente durante 30 minutos, mostrou sintomas graves. O Bovino $5599(0,5 \mathrm{~g} / \mathrm{kg})$ morreu independentemente da movimentação. Os dois bovinos mostraram os primeiros sin-

Quadro 1. Experimentos com Palicourea. marcgravii realizados em búfalos e bovinos

\begin{tabular}{|c|c|c|c|c|c|c|c|c|}
\hline $\begin{array}{c}\text { Identificação } \\
\text { do animal } \\
\text { (Reg.SAP) }\end{array}$ & $\begin{array}{c}\text { Peso } \\
(\mathrm{kg})\end{array}$ & $\begin{array}{c}\text { Data da } \\
\text { administração }\end{array}$ & Espécie & $\begin{array}{l}\text { Dose } \\
(\mathrm{g} / \mathrm{kg})\end{array}$ & $\begin{array}{l}\text { Início de sintomas } \\
\text { leves após começo } \\
\text { da administração }\end{array}$ & $\begin{array}{l}\text { Início de sintomas } \\
\text { graves após começo } \\
\text { da administração }\end{array}$ & $\begin{array}{l}\text { Manifestação de } \\
\text { sintomas graves }\end{array}$ & Desfecho \\
\hline 5591 & 232 & 20.10 .02 & Bubalina & 0,50 & - & - & - & Sem sintomas \\
\hline 5592 & 220 & 20.10 .02 & Bubalina & 1,00 & - & - & - & Sem sintomas \\
\hline 5582 & 293 & 21.10 .02 & Bubalina & 1,00 & - & - & - & Sem sintomas \\
\hline 5583 & 254 & 21.10 .02 & Bubalina & 2,00 & - & - & - & Sem sintomas \\
\hline 5584 (29529) & 229 & 29.10 .02 & Bubalino & 3,00 & - & $8 \mathrm{~h}$ & $1 \mathrm{~h} 28 \mathrm{~min}$. & Morreu \\
\hline 5595 (29524) & 210 & 22.10 .02 & Bubalina & 4,00 & $09 \mathrm{~h} 47 \mathrm{~min}$. & $28 \mathrm{~h} 17 \mathrm{~min}$. & $10 \mathrm{~min}$. & Morreu \\
\hline 5587 (29525) & 246 & 23.10 .02 & Bubalina & 6,00 & - & $08 \mathrm{~h} 15 \mathrm{~min}$. & $45 \mathrm{~min}$. & Morreu \\
\hline 5598 & 237 & 25.10 .02 & Bovina & 0,25 & & & & Sem sintomas \\
\hline 5599 (29528) & 256 & 24.10 .02 & Bovina & 0,50 & $17 \mathrm{~h} 23 \mathrm{~min}$. & 17 h $53 \mathrm{~min}$. & $09 \mathrm{~min}$. & Morreu \\
\hline 5597 (29526) & 165 & 23.10 .02 & Bovina & 2,00 & 07 h $22 \mathrm{~min}$. & 07 h $50 \mathrm{~min}$. & $03 \mathrm{~min}$. & Morreu \\
\hline
\end{tabular}




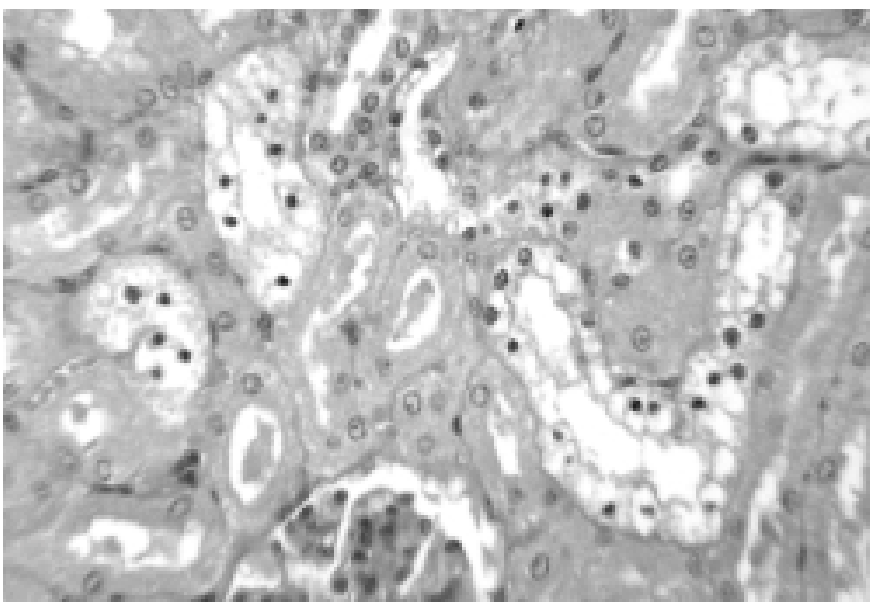

Fig. 1. Rim com degeneração hidrópico-vacuolar acentuada das células epiteliais dos túbulos uriníferos contornados distais em búfalo intoxicado por Palicourea marcgravii (Búfalo 5595). HE, obj. 25.

tomas graves 7 h 50 min. e 17 h 53 min. após o começo da administração da planta. A duração dos sintomas graves até a morte desses dois bovinos foi de $3 \mathrm{~min}$. e $9 \mathrm{~min}$., respectivamente. Esses dois bovinos, $28 \mathrm{~min}$. e $30 \mathrm{~min}$., respectivamente, antes das manifestações graves, mostraram sintomas leves como andar lento, ficando por muito tempo em decúbito esternal, com taquicardia, jugular saliente e pulsando e dispnéia após correr. Os sintomas graves de intoxicação, tanto nos búfalos como nos bovinos foram, quando o animal estava em pé, andar desequilibrado e queda ao solo; ficavam em decúbito lateral. Faziam então movimentos desordenados na tentativa de se levantar, movimentos de pedalagem intermitentes, tinham tremores musculares ocasionais, respiração ofegante e cada vez mais espaçada, às vezes com a boca aberta e a língua protrusa. Os achados de necropsia, tanto nos búfalos como nos bovinos, foram negativos. Os exames histopatológicos revelaram nos búfalos as seguintes alterações: no Búfalo 5584 (SAP 29525) no pulmão moderada congestão e moderado edema intra-alveolar, no Búfalo 5587 (SAP 29525) no pulmão leve a moderado enfisema alveolar e no Búfalo 5595 (SAP 29524) no pulmão moderado enfisema alveolar e no rim acentuada degeneração hidrópico-vacuolar das células epiteliais do túbulos contornados distais, caracterizada por picnose nuclear e o citoplasma vacuolizado; havia também lise de células epiteliais em alguns túbulos. Nos bovinos foram encontradas as seguintes alterações histológicas: no Bovino 5597 (SAP 29526) no rim moderada degeneração hidrópico-vacuolar (picnose nuclear e vacuolização do citoplasma) das células epiteliais dos túbulos uriníferos contornados distais.

Resumo dos dados dos experimentos com Palicourea marcgravii em búfalos

Búfalo 5587, macho, com $246 \mathrm{~kg}$, recebeu em 23.10.02, das 9:05h às 9:47h, $1476 \mathrm{~g}(6 \mathrm{~g} / \mathrm{kg})$, das folhas frescas de Palicourea marcgravii colhidas em 19.10.02 nos municípios de Rondon do Pará e Abel Figueiredo, Pará. Antes da administração temperatura (T) 38.9, frequiência cardíaca por minuto (C) 75 , frequiência respiratória por minuto $(\mathrm{R}) 30$, movimentos ruminais por minuto (Ru) $1 / 3$. Às 17:21h, um minuto após o início do primeiro exercício, o

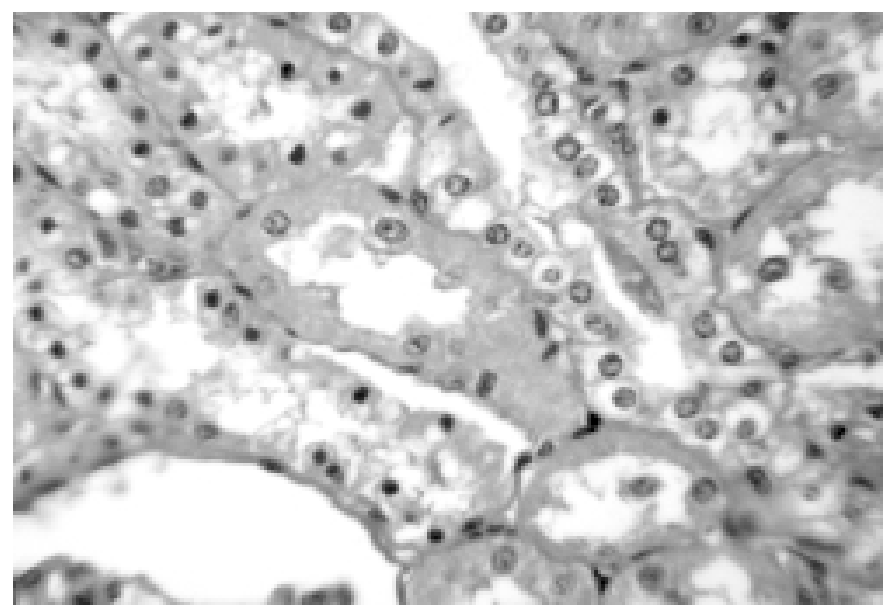

Fig. 2. Rim com degeneração hidrópico-vacuolar moderada das células epiteliais dos túbulos uriníferos contornados distais em bovino intoxicado por Palicourea marcgravii (Bov. 5597). HE, obj. 25.

animal apresentou tremores e caiu desordenadamente ficando logo em decúbito lateral, fazendo violentos movimentos de pedalagem. Às 17:27h assumiu o decúbito esternal, ficando nesta posição, calmo, até as 17:40h, quando se levantou. A jugular estava ingurgitada, pulsando; o animal urinou diversas vezes e defecou. Às 17:55h, quando tocado à cavalo, perdeu o equilíbrio e caiu, ficando inicialmente em decúbito esternal, logo em seguida em decúbito lateral, com respiração ofegante. Em seguida ficou em decúbito esternal, com o focinho apoiado no solo. Às 17:58h caiu de lado, esticou os membros, ficou com a cabeça em opistótono, teve tremores generalizado e fazia movimentos de pedalagem. Às 17:59 estava quieto, com a respiração espaçada, boca aberta, a cabeça em opistótono; fez mais alguns movimentos de pedalagem e às 18:05h estava morto. - Achados de necropsia: ausência de lesões. - Os exames histopatológicos (SAP 29525) revelaram no pulmão leve a moderado enfisema alveolar.

Búfalo 5595 , macho com $210 \mathrm{~kg}$, recebeu em 22.10.02, das $8: 28 \mathrm{~h}$ às $8: 48 \mathrm{~h}$, $840 \mathrm{~g}(4 \mathrm{~g} / \mathrm{kg})$ das folhas frescas de P.marcgravii colhidas em 19.10.02 nos municípios de Rondon do Pará e Abel Figueiredo, Pará. Antes da administração T 38.5, C 45, R 24, Ru 3/3. Quando tocado, à cavalo, das 16:15h às 16:30h, correu bem. A partir das 17:45h começou a apresentar sintomas leves, sob a forma de andar lento com os membros endurecidos, deitando-se logo. No dia seguinte, quando exercitado, a partir das 7:47h, logo demonstrou andar lento e as 7:57h não andou, mesmo tocado a cavalo. C 72 com arritmia. $R 48$. 8:50h. Sempre em decúbito esternal. Às 12:00h apresentou dificuldade em se locomover (quadrilátero de sustentação aberto, dificuldade de movimentos dos membros posteriores), e se deitou. Às 12:10h levantou-se e andou com dificuldade até o cocho de água, mas sem beber. Às 12:45h o animal teve tremores, falta de equilíbrio e ficou em decúbito lateral e às $12: 55 \mathrm{~h}$ estava morto. - Achados de necropsia: equimoses no endocárdio. Presença de muita espuma branca na traquéia e nos brônquios. Enfisema alveolar difuso. - Os exames histopatológicos (SAP 29524) revelaram moderado enfisema alveolar e no rim acentuada degeneração hidrópico-vacuolar das células epiteliais dos túbulos contornados distais, caracterizada por picnose nuclear e o citoplasma vacuolizado; há também lise de células epiteliais em alguns túbulos.

Búfalo 5584, macho com $229 \mathrm{~kg}$, recebeu em 29.10.02, das 22:00h às $22: 25 \mathrm{~h}, 687 \mathrm{~g}(3 \mathrm{~g} / \mathrm{kg})$ das folhas frescas colhidas em 19.10 .02 nos municípios de Rondon do Pará e Abel Figueiredo, Pará. Antes da administração T 38.6, C 80, R 20, Ru 1/2. Em 30.10.02 foi visto em decúbito lateral, fazendo movimentos de pedalagem. Às 6:02h assumiu o decúbito esternal, e logo em seguida se levantou, defecou, e ficou quieto em pé. Em seguida deu uns passos lentos. Às $6: 40 \mathrm{~h}$ de vez em quando dava uns passos com cuidado. Às 6:50 ficou em decúbito esternal e colocou o queixo no solo. Pouco tempo depois levantou a cabeça. Às $7: 18 \mathrm{~h}$, sem ter sido provocado, lenta- 
mente virou, ficando em decúbito lateral, com a respiração ofegante, deu uns berros: às vezes fazia movimentos de pedalagem. Às 7:21h apresentou tremores generalizados, a respiração, com a boca aberta, cada vez se tornou mais espaçada. O animal teve acessos de fortes movimentos de pedalagem intermitentes, a cabeça assumiu o opistótono e aos membros ficaram esticados. Havia tremores generalizados e às 7:28h o animal estava morto. - Achados de necropsia: ausência de lesões. - Os exames histopatológicos (SAP 29525) revelaram no pulmão moderada congestão e moderado edema intra-alveolar.

Resumo dos dados dos experimentos com Palicourea marcgravii em bovinos

Bovino 5599, fêmea com $256 \mathrm{~kg}$, recebeu em 24.10 .02 , das $14: 32 \mathrm{~h}$ às $14: 36 \mathrm{~h}, 128 \mathrm{~g}(0,5 \mathrm{~g} / \mathrm{kg})$ das folhas frescas de $P$. marcgravii, colhidas em 19.10.02 nos municípios de Rondon do Pará e Abel Figueiredo, Pará. Antes da administração T 39.5, C 64, R 25 e Ru 1/3. No dia seguinte, 25.10.02, ao término de 15 minutos de exercício, às 7:55h, o animal deitou-se em decúbito esternal, e só se levantou às 7:58h após ter sido tocado bastante. Urinava ao correr, e às 7:59h não quis mais correr. R 56 abdominal, jugular ingurgitada. Às 8:06h deitou-se precipitadamente e não quis mais se levantar. Às 8:07h levantou-se após ter sido tocado bastante, correu urinando, respiração ofegante, jugular ingurgitada, pulsando. C 148 com ritmo de galope, não se podendo distinguir entre a 1. e 2. bulha. Às 8:17h mais tranqüilo, no mesmo local. Às $8: 25 \mathrm{~h}$ de repente caiu, ficando logo em decúbito lateral, fazia movimentos desordenados. Ficou em decúbito esternal, balançando com a cabeça, meio inclinado, com a respiração ofegante. Caiu de lado, deu mugidos, a respiração estava ofegante, fêz leves movimentos de pedalagem. Às 8:31h respirava com a boca aberta, virou de lado com movimentos desordenados, tentou levantar-se, fez movimentos de pedalagem e às $8: 34 \mathrm{~h}$ estava morto. - Achados de necropsia: no lobo diafragmático uma área com enfisema alveolar. - Os exames histopatológicos (SAP 29528) revelaram no fígado a presença de alguns pequenos focos de necrose com infiltrados polimorfonucleares.

Bovino 5597, macho com $165 \mathrm{~kg}$, recebeu em 22.10.02, das 10;12h às 11:15h, $330 \mathrm{~g}(2 \mathrm{~g} / \mathrm{kg})$ das folhas frescas de P. marcgravii colhidas em 19.10 .02 nos municípios Rondon do Pará e Abel Figueiredo, Pará. Antes da administração T 40.0, C 80, R 32, Ru 2/2. Às 17:34h, 2 minutos após o primeiro exercício, não quais mais correr, só andava empurrado. Às 17:50h, novamente 2 minutos após reinício do exercício, deitou, e não quis levantar-se. Às 17:53h levantou, tocado a cavalo, não andou. Jugular ingurgitada. Às 17:55h deitou-se. Às 18:02h o animal, em decúbito esternal, teve movimentos desordenados, respiração ofegante, jugular bem saliente, caiu de lado, respirava com a boca aberta, cada vez mais espaçado, e às 18:05 estava morto. - Achados de necropsia: no rúmen presença de muitas folhas inteiras de $P$. marcgravii ainda reconhecíveis. - Os exames histopatológicos (SAP 29526) revelaram no rim moderada degeneração hidrópico-vacuolar (picnose nuclear e vacuolização do citoplasma) das células epiteliais dos túbulos contornados distais e no fígado grupos de células mais claras (macrófagos) como encontrado em bovinos mantidos em pastos de Brachiaria spp.

\section{DISCUSSÃO E CONCLUSÕES}

Pelos experimentos realizados pode se concluir que os búfalos são, aproximadamente, seis vezes mais resistentes à ação tóxica de Palicourea marcgravii do que os bovinos. Com base nestes dados pode-se concluir que o menor índice de mortes pela ação de plantas tóxicas em búfalos na Amazônia é, pelo menos em parte, devido a maior resistência do búfalo à ação tóxica de $P$. marcgravii. Outro fator responsável pelo menor número de búfalos que morrem por intoxicação por plantas poderia ser que seu habitat preferencial coincide com o habitat de Arrabidaea bilabiata, planta tóxica menos perigosa do que P. marcgravii. Em virtude destes achados, e com o intuito de diminuir os prejuízos causados por P. marcgravii, se- ria mais prudente criar bubalinos no lugar de bovinos em áreas onde ocorre $P$. marcgravii.

$\mathrm{A}(\mathrm{s})$ causa(s) da maior resistência do búfalo à ação tóxica de $P$. marcgravii merece $(\mathrm{m})$ ser investigada(s) para a eventual elaboração de métodos profiláticos da intoxicação em bovinos. A descoberta dos mecanismos de resistência do búfalo à ação de $P$. marcgravii, poderia levar à elaborarção de métodos que induzissem nos bovinos uma resistência maior a toxidez de P. marcgravii. De acordo com Riet-Correa \& Medeiros (2001) algumas das técnicas alternativas no controle das intoxicações por plantas são as seguintes: (1) vacinação, (2) controle biológico, (3) detoxificação microbiana no rúmen, (4) substâncias que neutralizam os princípios tóxicos e (5) aversão alimentar condicionada. Poderia se acrescentar ainda, métodos que impedissem ou diminuíssem a absorção do princípio tóxico pelo tubo digestivo e métodos que estimulassem processos de detoxicação do fígado ou por outros órgãos/sistemas, processos estes que foram sugeridos de ocorrerem na intoxicação por pirrolizidinas em ovinos, cobaias, coelhos e em outros animais de laboratório (Tokarnia et al. 2000). Ao nosso ver, o método mais promissor e que deve ser investigado em primeiro lugar, é relativo a mecanismos de detoxificação microbiana do ácido monofluroacético, o principio tóxico de $P$. marcgravii, no rúmen. A detoxificação ruminal tem sido utilizada com êxito para a profilaxia de algumas intoxicações por plantas, como é o caso da intoxicação por Leucaena leucocephala, que foi controlada na Austrália mediante a introdução de bactérias ruminais que degradam a di-hidroxi-piridona, que por sua vez é o resultado da degradação autolítica e microbiana da mimosina, o princípio ativo da planta.

Pesquisadores australianos modificaram geneticamente a bactéria ruminal Butyrivibrio fibrisolvens, mediante a introdução de um gene, isoladomde Moraxella sp, que codifica uma dehalogenase, capaz de hidrolizar fluoroacetato. A transferência de $B$. fibrisolvens geneticamente modificado para o rúmen de animais ingerindo plantas que contêm fluoroacetato, como é o caso de $P$. marcgravii, seria uma técnica viável de controle da intoxicação mediante a detoxificação ruminal do princípio ativo (Gregg et al. 1994, 1998). Em contatos preliminares o diretor responsável do consórcio responsável pela modificação da bactéria, declarou que tinha interesse em vender a tecnologia ao nosso país, porém seria necessário saber se no Brasil é possível importar essa bactéria geneticamente modificada. Caso positivo, seria indispensável realizar pesquisas sobre a viabilidade e metodologia para o uso desta bactéria em nosso meio.

Agradecimentos.- Ao Presidente da Associação de Criadores de Búfalos do Estado do Pará, Senhor Roberto Fonseca, e ao proprietário da Fazenda Agropecuária Santa Rita, Senhor William de Souza, pela doação de búfalos usados no presente estudo.

\section{REFERÊNCIAS}

Cunha M.R. 1987. Búfalo prova sua resistência à erva cafezinho. Búfalo em Evidência 1(3):2.

Gregg K., Cooper C. L., Schafer D. J., Sharpe H., Beard C.E., Allen G. \& Xu J. 
1994. Detoxification of the plant toxin fluoroacetate by a genetically modified rumen bacterium. Bio/Technology 12:1361-1365.

Gregg K., Hamdorf B., Henderson K., Kopecny J. \& Wong C. 1998. Genetically modified ruminal bacteria protect sheep from fluoracetate poisoning. Appl. Environ. Microbiol. 64 (9):3496-3498

Riet-Correa F. \& Medeiros R.M.T. 2001. Intoxicações por plantas em ruminan- tes no Brasil e no Uruguai: importância econômica, controle e riscos para a saúde pública. Pesq. Vet. Bras. 21(1):38-42.

Tokarnia C.H., Döbereiner J. \& Freitas M. 1979. Plantas Tóxicas da Amazônia a Bovinos e outros Herbívoros. INPA, Manaus.

Tokarnia C.H., Döbereiner J. \& Peixoto P.V. 2000. Plantas Tóxicas do Brasil. Editora Helianthus, Rio de Janeiro. 